\title{
A NEW BRACONID GENUS (HYMENOPTERA) PARASITIZING WEBSPINNERS (EMBIIDINA) IN TRINIDAD
}

\author{
By Scott R. Shaw ${ }^{1}$ AND Janice S. Edgerly ${ }^{2}$
}

Early in 1984, while conducting field studies on embiid behavior in the Arima valley of northern Trinidad, the junior author observed a braconid wasp ovipositing into the silk webs of an embiid, Clothoda urichi (Saussure) [Clothodidae]. The wasp and a paralyzed embiid were collected, and another wasp was successfully reared from that host. Specimens were sent to the senior author, then stationed at the National Museum of Natural History (USNM), who determined it to be a new braconid genus. A search of the USNM collection yielded no comparable specimens; however, during a subsequent search of the Museum of Comparative Zoology (MCZ) collection a specimen of a different, but related, species was found. Shenefelt (1980) provided a comprehensive index to recorded braconid hosts, which does not include any Embiidina. Callan (1952) mentioned that he collected numerous white cocoons from embiid webs in Trinidad, and he reared a braconid from these which was identified only as "Apanteles sp." He suggested that these were parasites of lepidopterous larvae that sometimes live under the silk, not parasites of the webspinners. The establishment of this new genus as a parasite of webspinners therefore provides a totally new host order record for the family Braconidae.

The morphological terminology used in this paper is mostly that of Marsh (1965, 1982) and van Achterberg (1974). Microsculpture terminology is that of Harris (1979). Taxonomic descriptions presented in this paper are solely the work of the senior author, while life history information on the parasite and its host was provided by the junior author.

\footnotetext{
'Museum of Comparative Zoology, Harvard University, Cambridge, Massachusetts 02138.

${ }^{2}$ Department of Entomology, Comstock Hall, Cornell University, Ithaca, New York 14853.

Manuscript received by the editor June 12, 1985.
} 


\section{Genus Sericobracon Shaw, NEw GENUS}

Type-species: Sericobracon arimaensis Shaw

Head: Subcubical, broader than long; lower clypeal margin truncate; labrum glabrous, slightly concave; mandibles shorter than $1 / 2$ malar space, barely meeting at tips when closed; maxillary palpi 6-segmented; labial palpi 4-segmented; vertex strigate; occipital carina present.

Mesosoma: Mesonotal lobes coriaceous, notauli scrobiculate, meeting posteriorly in a wide rugose area; scutellar disc smooth; scutellar furrow 4-6 foveate; mesopleuron coriaceous, subalar furrow and sternaulus scrobiculate; prepectal carina present; propodeum with basal carina, fork of basal carina, and lateral carinae well developed, basolateral areas smooth (Figs. 2-3); foretibia apparently without stout spines or pegs; hindcoxa with an anteroventral tubercle; forewing (Fig. 1) with two intercubital crossveins, although second intercubitus is mostly desclerotized; first intercubitus desclerotized at lower end; recurrent vein entering first cubital cell; brachial cell open apically; hindwing (Fig. 1) with radiella, cubitella, postnervellus, nervellus, and submediella absent.

Metasoma: Dorsope present (Figs. 4-5); fused terga 2+3 with 2 transverse scrobiculate furrows, the anterior furrow separating terga 2 and 3, the posterior furrow bisecting tergum 3; terga 3-7 smooth and shining; 6 or 7 exposed terga; ovipositor length varying from 0.6 to $1.2 \times$ metasoma length (excluding ovipositor).

Etymology: The name is masculine, derived from "sericum" (L.) meaning silk, in reference to the silk webs of the embiid host of the type-species.

Remarks: Based on patterns of body sculpturing we place Sericobracon in the subfamily Doryctinae, where it is allied to Heterospilus Haliday. Some neotropical Heterospilus species are remarkably similar in sculpturing of the mesonotum, propodeum, and metasomal tergites (e.g. Marsh 1982, figs. 7-8). Sericobracon also agrees with Heterospilus in having the lower end of the first intercubitus desclerotized. Sericobracon may be distinguished from other doryctine genera by the absence of stout spines or pegs on the foretibia.

Subfamilial placement of Sericobracon is problematic in that recent authors (e.g. Marsh 1965; van Achterberg 1976, 1984) have cited stout foretibial spines or pegs as a defining character of the 
Doryctinae. However, according to van Achterberg (pers. comm.) the stout foretibial pegs of Doryctinae are probably related to living in wood or other hard substrates as larvae. Thus, it might be expected that a species not associated with larvae in wood has no distinct pegs (a secondary loss).

Aside from the above mentioned similarities, Sericobracon agrees with the Doryctinae in several additional characters. These include: hindcoxa with an anteroventral tubercle, dorsope present, and paralysis of the host prior to egg deposition.

Most Doryctinae are parasites of wood-boring beetle larvae; however, Marsh (1982) notes that Heterospilus show an unusually wide range of host associations across three insect orders: Coleoptera, Lepidoptera, and Hymenoptera. In nearly all cases the hosts have cryptic boring habits, usually in plant stems or branches. If Sericobracon is closely related to Heterospilus, then the host shift to Embiidina may not be so unusual. It is simply a shift to a phylogenetically unrelated host, which occurs in the same microhabitat.

\section{Sericobracon arimaensis, NEW SPECIES}

(Figs. 1, 2, 4)

Holotype. Female, Trinidad: Arima valley, northern range, 4 miles north of Arima, Simla Research Station, on silk webs of embiid Clothoda urichi, April 1984, (J. S. Edgerly). [Ithaca]

Description of the holotype female: Body length $3.0 \mathrm{~mm}$; flagellum 20-segmented; malar space $1 / 3$ eye height; scutellar furrow 4foveate; apical area of propodeum (within the areola) rugose (Fig. 2 ); first tergum $3 / 4 \times$ as long as wide at apex, transversely striate basomedially (Fig. 4); tergum 2 longitudinally striate especially anteriorly; ovipositor length $1.1 \times$ metasoma length.

Color: Head golden brown except ocellar triangle black; flagellum beyond $\mathrm{F} 4$ dark brown; palpi pale white; mesosoma golden brown except metanotum, metapleuron, and propodeum entirely black; scutellar disc and mesopleuron suffused with black; legs pale yellowish brown; wing venation dark brown; metasoma yellowish brown except tergum 1 and base of tergum 2 entirely black; terga 3-5 mostly suffused with black; ovipositor sheaths dark brown.

Paratype females: Essentially same as holotype except scutellar furrow 6-foveate, tergum 2 more coarsely rugose posteriorly, and tergum 3 sometimes entirely black. 

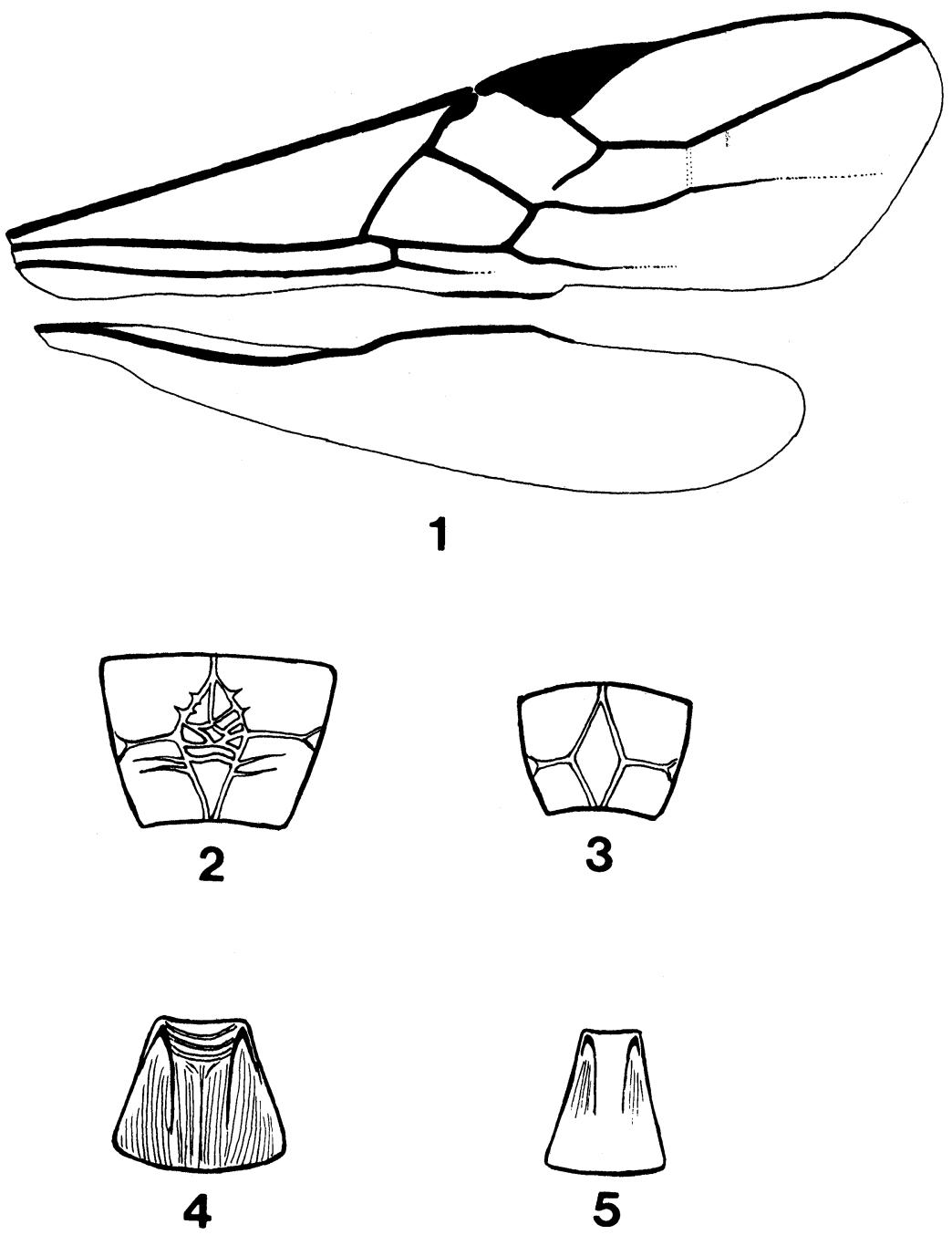

Figure 1. Wings of Sericobracon arimaensis. Figure 2. Sericobracon arimaensis, propodeum. Figure 3. Sericobracon evansi, propodeum. Figure 4. Sericobracon arimaensis, tergum 1. Figure 5. Sericobracon evansi, tergum 1. 
Male: Unknown.

Paratype data: 1 female, same data as holotype except collected 1 Feb. 1984, ovipositing in web of embiid Clothoda urichi, [MCZ]; 1 female, same data as holotype except reared from paralyzed embiid collected 1 Feb., adult wasp emerged 19 Feb. 1984, [MCZ]; 1 female, Trinidad, Lalaja Rd., 23 June 1984, caught on silk of Clothoda urichi, (J. S. Edgerly), [USNM].

Remarks: $S$. arimaensis may be distinguished from $S$. evansi by its more coarsely sculptured propodeum and terga 1-2 (figs. 2-5).

Host: Reared from an embiid, Clothoda urichi (Saussure). The morphology and biology of this species is discussed by Ross (1944) and Callan (1952).

Life history: Clothoda urichi (Saussure), an abundant species in Trinidad, spins silk on vertical objects, generally trees, that support the growth of algae, the food of this embiid. They construct conspicuous silken webs beneath which they live in groups, ranging from one mother with her offspring to 25 or more females with their young. On February 1, 1984 at the Simla Research Station in the Arima Valley, a braconid wasp was observed to penetrate embiid silk with her ovipositor. A paralyzed adult female embiid was found directly beneath the silk under the wasp. She was collected and placed in a petri dish in the laboratory. The female remained paralyzed until February 8 when the endoparasitic wasp larva killed the embiid and emerged to spin a white silken cocoon $(.6 \mathrm{~cm})$, within which it pupated. The adult wasp emerged from the cocoon on February 19.

Distribution: Trinidad.

Etymology: The name refers to the Arima valley of Trinidad, the type-locality.

\section{Sericobracon evansi, NEW SPECIES}

(Figs. 3, 5)

Holotype. Female, Virgin Islands: St. Croix, E. side of Blue Mt., 14 Feb. 1967, (H. E. Evans). [MCZ]

Description of holotype female: Body length $2.5 \mathrm{~mm}$; flagellum 18-segmented; malar space slightly less than $1 / 3$ eye height; scutellar furrow 6-foveate; apical area of propodeum mostly smooth (Fig. 3); length of tergum 1 equal to width at apex, smooth basomedially (Fig. 5); tergum 2 smooth; ovipositor length $0.6 \times$ metasoma length. 
Color: Head golden brown except occiput, temples, and vertex suffused with black; flagellum beyond F6 dark brown; palpi white; mesosoma golden brown except metapleuron entirely black; scutellar disc, metanotum, propodeum, mesopleuron, and pronotum suffused with black; legs pale yellowish brown to pale white; wing venation dark brown; metasoma yellowish brown except basal 3/4 of tergum 1 and entire tergum 3 completely black; apical $1 / 4$ of tergum 1 and terga 4-6 suffused with black; ovipositor sheaths black.

Male: Unknown.

Remarks: $S$. evansi may be distinguished from $S$. arimaensis by its smoother propodeum and terga 1-2 (Figs. 2-5).

Host: Unknown.

Distribution: Virgin Islands.

Etymology: Named for Howard Ensign Evans, eminent hymenopterist, gifted natural history writer, and collector of the holotype specimen.

\section{ACKNOWLEDGMENTS}

Special thanks to Dr. C. van Achterberg, Rijksmuseum van Natuurlijke Historie, Leiden, who examined a paratype of Sericobracon arimaensis and provided his opinion on its phylogenetic placement. Additional thanks are due to Dr. P. M. Marsh, Systematic Entomology Laboratory, U.S. Department of Agriculture, c/o National Museum of Natural History, Washington D.C., and Dr. W. R. M. Mason, Biosystematics Research Institute, Agriculture Canada, Ottawa, Ontario, who reviewed the manuscript and provided their helpful comments. Field work by the junior author was supported by grants from the National Academy of Sciences, Sigma Xi, and the National Science Foundation (NSF Doctoral Dissertation Improvement Grant BSR-8312897).

\section{SUMMARY}

Sericobracon Shaw, a new doryctine braconid genus from the Neotropical region, is described and illustrated. Two new species are included in the genus: $S$. arimaensis and $S$. evansi. the type-species, $S$. arimaensis, was reared from Clothoda urichi (Saussure), the first record of Braconidae parasitizing Embiidina. 


\section{Literature Cited}

AChTERBerg, C. van

1974. The features of the petiolar segment in some Braconidae. Ent. Berich. 34: 213.

1976. A preliminary key to the subfamilies of the Braconidae (Hymenoptera). Tijdsch. Ent. 119: 33-78.

1984. Essay on the phylogeny of Braconidae (Hymenoptera: Ichneumonoidea). Ent. Tidskr. 105: 41-58.

Callan, E. McC.

1952. Embioptera of Trinidad with notes on their parasites. Trans. Ninth Int. Congr. Ent. 1: 483-489.

HARRIS, R. A.

1979. A glossary of surface sculpturing. Occasional Papers in Entomology, No. 28. State of California, Dept. of Food and Agriculture, Sacramento. $31 \mathrm{pp}$.

MARSh, P. M.

1965. The Nearctic Doryctinae. I. A review of the subfamily with a taxonomic revision of the tribe Hecabolini (Hymenoptera: Braconidae). Ann. Entomol. Soc. Am. 58: 668-699.

1982. Two new species of Heterospilus (Hymenoptera: Braconidae) from Mexico being introduced against the cotton boll weevil, Anthonomus grandis (Coleoptera: Curculionidae). Proc. Entomol. Soc. Wash. 84: 849-854.

Ross, E. S.

1944. A revision of the Embioptera, or webspinners, of the New World. Proc. U.S. Natn. Mus. 94: 401-504.

SHENEFELT, R. D.

1980. Hymenopterorum catalogus, part 16. Braconidae 11. Introduction, guide to host names, and index to braconid names. W. Junk, The Hague, Netherlands, 384 pp. 

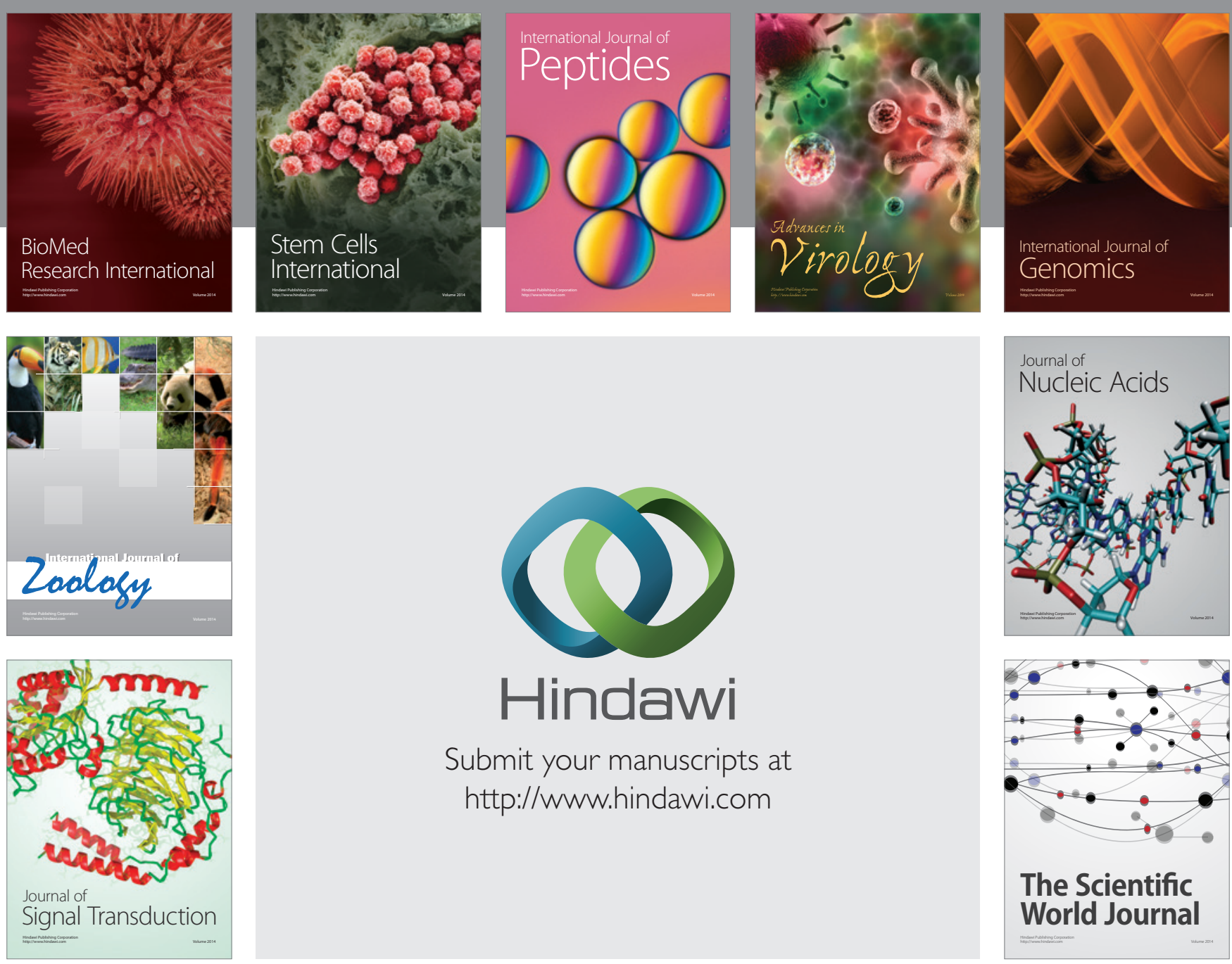

Submit your manuscripts at

http://www.hindawi.com
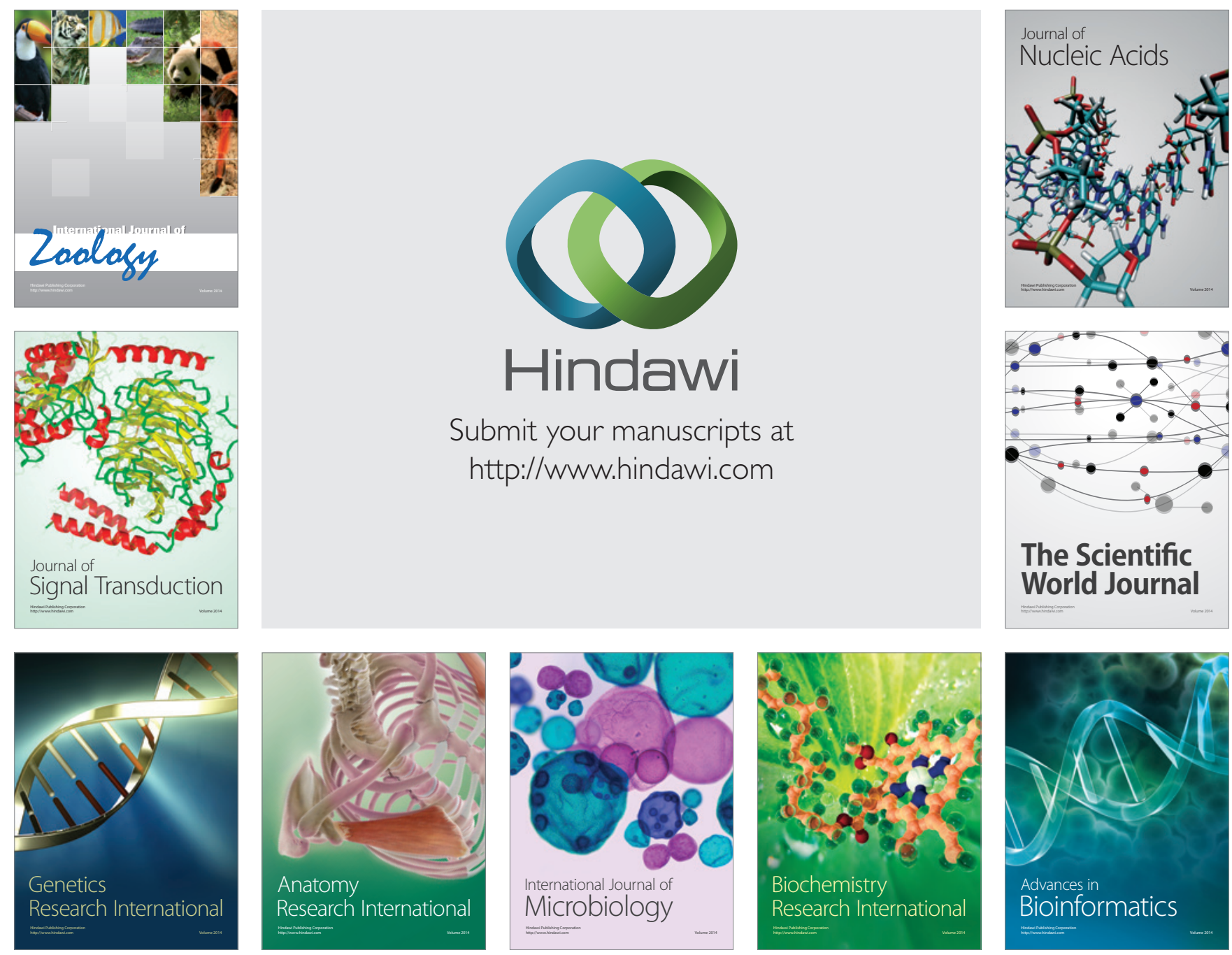

The Scientific World Journal
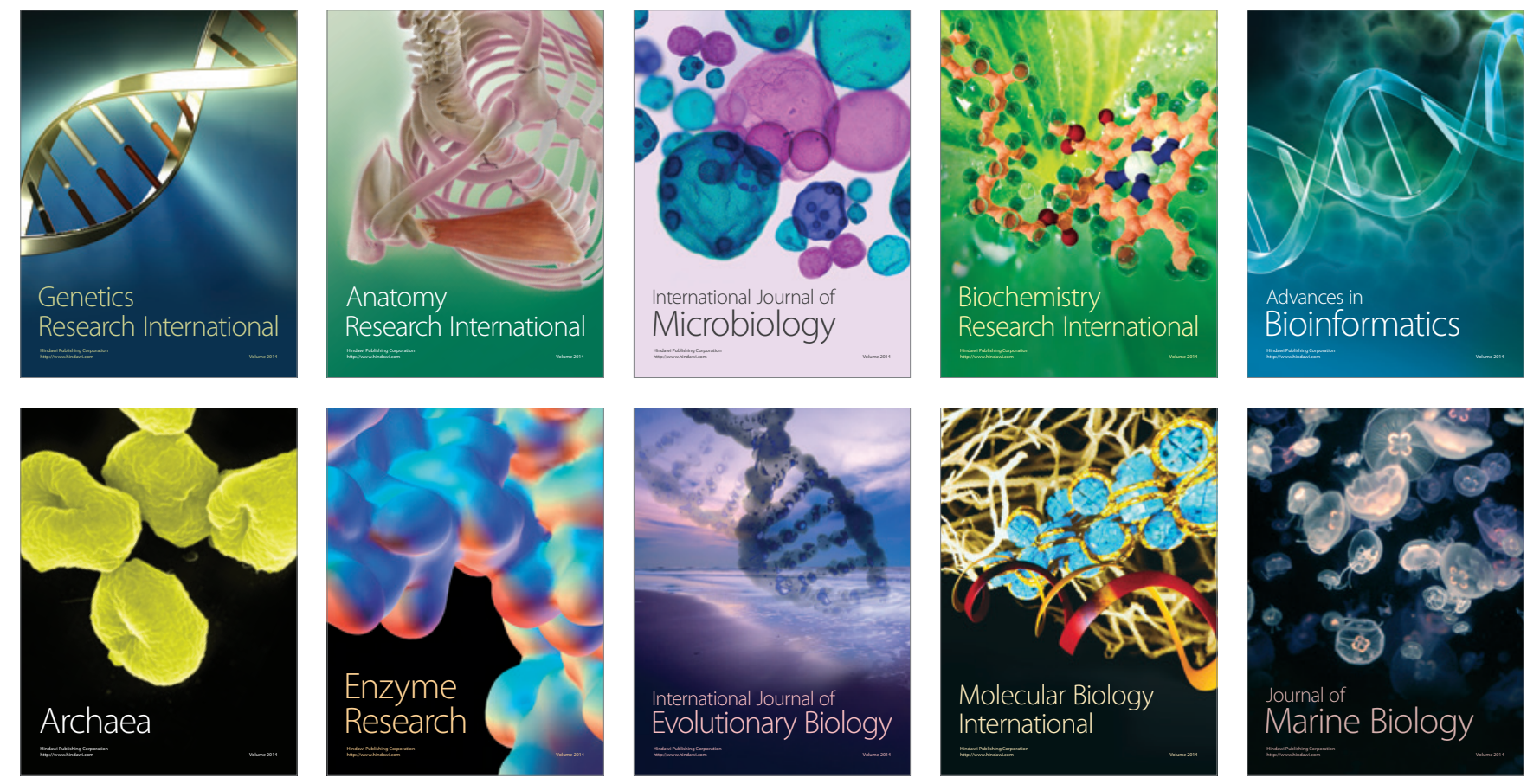